\title{
In vitro antimicrobial activity of Sodium hypochlorite, Chlorhexidine gluconate and Octenidine Dihydrochloride in elimination of microor- ganisms within dentinal tubules of primary and permanent teeth
}

\author{
Resmiye-Ebru Tirali ${ }^{1}$, Haluk Bodur ${ }^{2}$, Gülden Ece ${ }^{3}$
}

${ }^{1}$ DDS, PhD. Assistant Professor, Department of Pediatric Dentistry, Faculty of Dentistry, University of Baskent, Ankara, Turkey

${ }^{2}$ DDS. Assistant Professor Associate Professor, Department of Pediatric Dentistry, Faculty of Dentistry, University of Gazi, Ankara, Turkey

${ }^{3}$ DDS, PhD. Consultant, Department of Microbiology, School of Medicine, University of Gazi, Ankara, Turkey

Correspondence:

11 Sokak No 26

Bahcelievler 06490 Ankara

ebru_aktepe@hotmail.com

Received: 24/02/201

Accepted: $17 / 04 / 2011$
Tirali RE, Bodur H, Ece G. In vitro antimicrobial activity of Sodium hypochlorite, Chlorhexidine gluconate and Octenidine Dihydrochloride in elimination of microorganisms within dentinal tubules of primary and permanent teeth. Med Oral Patol Oral Cir Bucal. 2012 May 1;17 (3):e51722.

http://www.medicinaoral.com/medoralfree01/v17i3/medoralv17i3p517.pdf

\section{Article Number: $17566 \quad$ http://www.medicinaoral.com/}

(C) Medicina Oral S. L. C.I.F. B 96689336 - pISSN $1698-4447$ - eISSN: $1698-6946$

eMail: medicina@medicinaoral.com

Indexed in:

Science Citation Index Expanded

Journal Citation Reports

Index Medicus, MEDLINE, PubMed

Scopus, Embase and Emcare

Indice Médico Español

\begin{abstract}
The aim of this study was to evaluate the effectiveness of different irrigation solutions at different time intervals for the elimination of E.faecalis and C.albicans penetrated into the dentine tubules of primary and permanent teeth in vitro.

The $4 \mathrm{~mm}$ primary and permanent teeth sections were sterilized and contaminated with a mixture of E.faecalis and C.albicans strains. After the application of different irrigation solutions (Sodium hypochlorite, Chlorhexidine gluconate, Octenidine Dihydrochloride, saline) to the contaminated tooth sections according to study groups, neutralizers were applied for inactivation of the solutions after $30 \mathrm{sec}, 1 \mathrm{~min}$ and $5 \mathrm{~min}$. Dentine shavings were placed into TSB and $10 \mu \mathrm{L}$ from each tube was inoculated on agar plates, followed by an incubation period of $24 \mathrm{~h}$ at $37^{\circ} \mathrm{C}$. The colonies were counted macroscopically. The results were compared by using Kruskal-Wallis and Mann Whitney U tests, with a significance level at $\mathrm{p}<0.05$.

Among the irrigation solutions that were tested against E.faecalis on primary and permanent teeth, the most effective one was found as 5-minute application of $0.1 \%$ Octenidine Dihydrochloride. The antibacterial effects of the tested solutions on the same time periods against C.albicans revealed no significant difference.

There were no statistically significant differences between primary and permanent teeth with respect to the antimicrobial activity of the tested solutions. Moreover, Octenidine Dihydrochloride may be used as an alternative endodontic irrigant.
\end{abstract}

Key words: Chlorhexidine gluconate, dentine tubules, irrigation solutions, Octenidine Dihydrochloride, Sodium hypochlorite. 


\section{Introduction}

Routine endodontic procedures such as instrumentation of the pulp space may remove a limited part of the infecting bacteria and their substrate of necrotic pulp debris. In addition to this situation with the anatomical complexities of many root canals and the limitations in access by therapeutic agents to the microcanal system, this can be quite challenging (1).

Furthermore, microorganisms may remain in the dentinal tubules, grooves and other irregularities of the root canal system. Once they remain in sufficient numbers, and under an adequately supportive environment, they may multiply and re-establish clinical contamination of the pulp space (2). Therefore, several irrigation solutions have been recommended for use in combination with root canal preparation. An irrigant serves to flush out debris from the instrumented root canals, dissolve organic tissue remnants, disinfect the root canal space, provide lubrication during instrumentation and remove smear layer without causing irritation to the biological tissues (3).

Premature loss of a primary tooth may cause many functional problems (4). One of the treatment choices of pulpally-involved primary teeth is non-vital pulp therapy. There are a few data exist regarding the use of irrigation solutions for the endodontic therapy of primary teeth (5).

The most commonly investigated agent, which has been accepted as the gold standard for the irrigation of root canal space, is sodium hypochlorite $(\mathrm{NaOCl})$ because of its clinical efficacy in endodontic therapy (3). It has solvent activity for both necrotic and vital tissues (6). However there are still some concerns with respect to the toxic effects (7), bad smell and taste, corrosive potential (8) and allergic reactions (9).

Chlorhexidine gluconate, has been suggested as an endodontic irrigant because of its antibacterial effects, and lower cytotoxicity but greater substantivity than $\mathrm{NaOCl}$, and efficient clinical performance (10).

Octenidine hydrochloride (OCT), developed by Sterlig Winthrop Research Institute, is a bispyridine derivative, i.e., N,N'-[1,10-decanediyldi-1(4H)-pyridinyl-4-ylidene] bis(1-octanamine) dihydrochloride. The existing data suggest that a mouthrinse containing $0.1 \%$ OCT may be capable of exerting beneficial clinical effects upon plaque accumulation and gingivitis (11). OCT used in the form of mouth rinse was reported to inhibit dental plaque and caries both in rats (12) and humans (11). It has been demonstrated that OCT appears to be more effective than chlorhexidine as a means for prolonged bacterial anti-adhesive activity (13). OCT has been suggested as an endodontic irrigant based on its antimicrobial effects and lower cytotoxicity (14).

E.faecalis was chosen as one of the test microorganisms in this experiment for the following reasons: (I) it is a well-recognized pathogen associated with persistent apical periodontitis in endodontically treated teeth (15); (II) it is resistant to $\mathrm{NaOCl}$, especially at low concentrations (16); (III) it readily colonizes in dentinal tubules and can penetrate to the entire width of dentin; and (IV) it is easy to culture and it grows rapidly (17).

The other test microorganism was C.albicans for this experiment. Microbiological investigations have shown that yeast may be present in the microflora of apical periodontitis (18) and cause persistent apical periodontitis (19). Its ability to invade dentinal tubules and resistance to commonly used intracanal medicaments may help to explain why C.albicans has been associated with the cases of persistent root canal infections (20).

The aim of this study was to evaluate the effectiveness of various irrigation solutions at different time intervals for the elimination of E.faecalis and C.albicans penetrated into the dentine tubules of primary and permanent teeth in vitro.

\section{Materials and Metods}

Eighty primary and eighty permanent extracted single rooted human teeth were used for this experiment. Their crowns and the apical parts were removed with a water-cooled diamond and the fragments standardized to a length of $4 \mathrm{~mm}$. They were placed in $0.5 \% \mathrm{NaOCl}$ for $24 \mathrm{hr}$ to implement surface disinfection. The internal diameter was then standardized by enlarging the root canals with an ISO 033 round bur (Horico, Berlin, Germany). The specimens were kept in sterile saline throughout the whole experimental procedures to avoid dehydration. The smear layer formed in the canal walls during endodontic instrumentation was removed by soaking in an ultrasonic bath with $17 \%$ EDTA (Pulpdent, Watertown, USA) for 5 min followed by the application of $5.25 \% \mathrm{NaOCl}$ (Gazi University, Faculty of Pharmacy, Ankara, Turkey) for $5 \mathrm{~min}$. The specimens, were placed in test tubes (20 primary or permanent teeth per tubes) containing $3 \mathrm{ml}$ of Brain Heart Infusion Broth (BHIB, Fluka, BioChemika 53286 Buchs, Switzerland) and autoclaved three times at $121^{\circ} \mathrm{C}$ for $30 \mathrm{~min}$.

C.albicans (ATCC 10231) were cultivated in Saboroud Dextrose (SDA, Biolab 20500, Budapest, Hungary) broth and E.faecalis (ATCC 29212) were cultivated in Tryptone Soya Broth (TSB, Lab M 0655052, Bury, Lancashire), respectively for $48 \mathrm{~h}$ and then cultured in Brain Heart Infusion Broth (BHIB, Fluka, Bio Chemika, 53286 Buchs, Switzerland) in an anaerobic chamber at $37^{\circ} \mathrm{C}$ for $48 \mathrm{~h}$. Suspensions of C.albicans and E.faecalis had the optical density adjusted spectrophotometrically to approximately $1.5 \times 10^{8}$ colony-forming units (cfu) $\mathrm{mL}^{-1}$. Then $1.5 \mathrm{~mL}$ of C.albicans suspension and 1.5 $\mathrm{mL}$ of E.faecalis suspension were collected in a single tube containing approximately $1.5 \times 10^{8} \mathrm{~mL}^{-1}$ of each microorganism. Sterile pipettes were used to remove $3 \mathrm{~mL}$ 
sterile BHI from test tubes and replace it with $3 \mathrm{~mL}$ of bacterial inoculum. The tubes were closed and kept at $37^{\circ} \mathrm{C}$ for 21 days. The medium was changed every 3 days to ensure viability of the microorganisms. The purity of the cultures was checked at intervals. To confirm root canal infection, Four specimens (2 for primary, 2 for permanent teeth) were submitted to the same initial instrumentation and contamination procedures, and were then observed under scanning electron microscopy (SEM; JSM 6400, Tokyo, Japan; (Fig. 1)

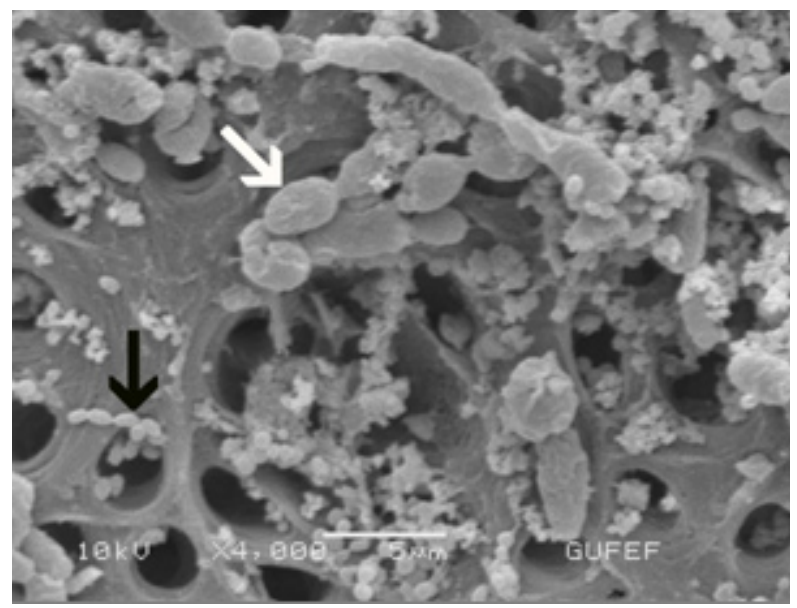

Fig. 1. Photomicrograph of root canals contaminated with E.faecalis ( black arrow) and C.albicans (white arrow). (x4000).

After infection, the specimens were randomly divided into 10 groups (each group contains 8 permanent and 8 primary teeth), according to the intracanal irrigants and different time intervals.

- Group 1: $1 \mathrm{~mL} 5.25 \% \mathrm{NaOCl} \rightarrow 30 \mathrm{sec}$

- Group 2: $1 \mathrm{~mL} \mathrm{5.25 \%} \mathrm{NaOCl} \rightarrow 1 \mathrm{~min}$

- Group 3: $1 \mathrm{~mL} \mathrm{5.25 \%} \mathrm{NaOCl} \rightarrow 5 \mathrm{~min}$

- Group 4: $1 \mathrm{~mL}$ 0.1\% Oct $\rightarrow 30 \mathrm{sec}$

- Group 5: $1 \mathrm{~mL}$ 0.1\% Oct $\rightarrow 1 \mathrm{~min}$

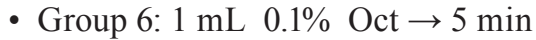

- Group 7: $1 \mathrm{~mL} \mathrm{2 \%} \mathrm{CHX} \rightarrow 30 \mathrm{sec}$

- Group 8: $1 \mathrm{~mL} \mathrm{2 \%} \mathrm{CHX} \rightarrow 1 \mathrm{~min}$

- Group 9: $1 \mathrm{~mL}$ 2\% CHX $\rightarrow 5 \mathrm{~min}$

- Group 10: $1 \mathrm{~mL}$ saline $\rightarrow 5 \mathrm{~min}$

The solutions prepared for neutralizing the tested irrigants in order to prevent continued action of the irrigants were ; the mixture of 3\% Tween 80 (Merk, Darmstadt, Germany), 0.3\% Lecithin (Aklar Kimya, Ankara, Turkey) and 0.1\% Cystein (Merk, Darmstadt, Germany) was used for Octenisept (OCT,0.1\% Octenidine hydrochloride; Schülke \& Mayr, Nordersdedt, Germany) (21) while $0.6 \%$ Sodium thiosulfate (Aklar Kimya, Ankara, Turkey) was used for $\mathrm{NaOCl}$ and $0.3 \%$ Lecithin and 3\% Tween 80 were used for Chlorhexidine gluconate (CHX, Drogsan, Ankara, Turkey) (22) (Table 1).
Table 1. The tested irrigating solutions with the corresponding neutralizing agents.

\begin{tabular}{|c|c|}
\hline Tested solutions & Neutralizing agents \\
\hline $0.1 \% \quad$ OCT & $\begin{array}{l}3 \% \text { Tween } 80 \\
0.3 \% \text { Lecithin } \\
0.1 \% \text { Cystein }\end{array}$ \\
\hline $5.25 \% \quad \mathrm{NaOCl}$ & $0.6 \%$ Sodium thiosulfate \\
\hline $2 \% \quad \mathrm{CHX}$ & $\begin{array}{l}0.3 \% \text { Lecithin } \\
3 \% \text { Tween } 80\end{array}$ \\
\hline
\end{tabular}

The tooth sections were held with sterile clamps and irrigated with syringe. At the end of each test period, sterile round burs (ISO 035) were used for cutting from the irrigated surface. The specimens were held with steril clamps. The dentin shavings obtained with each bur were collected in a separate test tube containing 1 $\mathrm{mL}$ of TSB broth. The burs were weighed before and after the collection of dentine samples in an attempt to standardize the volume of the dentine chips removed by each bur $(0.003 \pm 2 \times 104 \mathrm{mg})$. The round burs were placed in the tubes as well. After this period, $10 \mu \mathrm{L}$ of each tube was inoculated on BHIB agar plates, and left at $37^{\circ} \mathrm{C}$ for 24 hours in anaerobical gaseous condition to investigate all possible bacterial growth. All assays were repeated three times. The purity of the positive cultures was macroscopically evaluated. The results were compared by using Kruskal-Wallis and Mann Whitney U tests, with a significance level at $\mathrm{p}<0.05$.

\section{Results}

The medians of CFU mL $\mathrm{mL}^{-1}$ of E.faecalis after the application of the tested irrigation solutions at different contact times are given in (Tables 2 and 3). There were no significant differences between primary and permanent teeth in any of the tested groups $(\mathrm{p}>0.05)$. Application of $0.1 \%$ OCT for $5 \mathrm{~min}$. was shown to be the most effective way of eliminating E.faecalis that penetrated into the dentine tubules of primary and permanent teeth in vitro $(\mathrm{p}<0.05)$.

For primary teeth, there was a significant difference between the tested irrigation solutions. The most effective one was $0.1 \%$ OCT, while $5.25 \% \mathrm{NaOCl}$ appeared to be the least effective irrigant. Five minute was found as the most efficient duration of application $(\mathrm{p}<0.05)$.

The medians of CFU mL-1 of C.albicans after the application of the tested irrigation solutions at different contact times are given in (Tables 4 and 5). Similar to the results with E.faecalis, there is no significant differences between primary and permanent teeth $(\mathrm{p}>0.05)$. For C.albicans there isn't significant difference between different time durations of applications. Significant differences were found between all the tested solutions and the negative control group (saline solution) $(\mathrm{p}<0.05)$. 
Table 2. Mean values of $\mathrm{CFU} \mathrm{mL} \mathrm{mL}^{-1}$ of E.faecalis after tested irrigation solutions application to the primary teeth for different contact times.

\begin{tabular}{|l|c|c|c|c|}
\hline Time & $\begin{array}{c}\mathbf{5 , 2 5} \% \text { NaOCl } \\
\text { MeanValue } \\
\text { (Standard deviation) }\end{array}$ & $\begin{array}{c}\mathbf{0 , 1} \text { \%OCT } \\
\text { Mean Value } \\
\text { (Standard deviation) }\end{array}$ & $\begin{array}{c}\mathbf{2 , 0 \%} \text { KHX } \\
\text { Mean Value } \\
\text { (Standard deviation) }\end{array}$ & $\begin{array}{c}\text { Saline } \\
\text { Mean Value } \\
\text { (Standard deviation) }\end{array}$ \\
\hline $\mathbf{3 0}$ sec & $114,25(44,49)(a, A)$ & $33,25(17,44)(a, B)$ & $60,25(9,00)(a, C)$ & \\
$\mathbf{1}$ min & $88,37(37,63)(a, A)$ & $22,12(13,66)(a, B)$ & $42,50(10,58)(b, C)$ & $1928,75(577,27)(D)$ \\
$\mathbf{5}$ min & $36,25(18,37)(b, A)$ & $6,12(4,54)(b, B)$ & $10,12(5,74)(c, C)$ & (D) \\
\hline
\end{tabular}

*Different letters indicate significant difference (Kruskal-Wallis $\mathrm{P}<.05$ ). Capital letters indicate differences in horizontal direction. Lower-case letters indicate differences in vertical directions.

Table 3. Mean values of CFU mL $\mathrm{m}^{-1}$ of E.faecalis after tested irrigation solutions application to the permanent teeth for different contact times.

\begin{tabular}{|l|c|c|c|c|}
\hline Time & $\begin{array}{c}\mathbf{5 , 2 5} \% \mathbf{\% a O C l} \\
\text { Mean Value } \\
\text { (Standard deviation) }\end{array}$ & $\begin{array}{c}\mathbf{0 , 1 \%} \text { OCT } \\
\text { Mean Value } \\
\text { (Standard deviation) }\end{array}$ & $\begin{array}{c}\mathbf{2 , 0 \%} \text { KHX } \\
\text { Mean Value } \\
\text { (Standard deviation) }\end{array}$ & $\begin{array}{c}\text { Saline } \\
\text { Mean Value } \\
\text { (Standard deviation) }\end{array}$ \\
\hline 30 sec & $123,25(45,31)(\mathrm{a}, \mathrm{A})$ & $31,25(16,92)(\mathrm{a}, \mathrm{B})$ & $63,62(17,86)(\mathrm{a}, \mathrm{C})$ & \\
$\mathbf{1} \mathbf{~ m i n}$ & $93,62(32,70)(\mathrm{a}, \mathrm{A})$ & $22,12(15,77)(\mathrm{a}, \mathrm{B})$ & $50,25(19,59)(\mathrm{a}, \mathrm{C})$ & \\
$\mathbf{5} \mathbf{~ m i n}$ & $17,12(5,38)(\mathrm{b}, \mathrm{A})$ & $5,75(3,24)(\mathrm{b}, \mathrm{B})$ & $13,87(6,28)(\mathrm{b}, \mathrm{A})$ & $2182,50(858,00)(\mathrm{C})$ \\
\hline
\end{tabular}

*Different letters indicate significant difference (Kruskal-Wallis $\mathrm{P}<.05$ ). Capital letters indicate differences in horizontal direction. Lower-case letters indicate differences in vertical directions.

Table 4. Mean values of $\mathrm{CFU} \mathrm{mL} \mathrm{m}^{-1}$ of C.albicans after tested irrigation solutions application to the primary teeth for different contact times.

\begin{tabular}{|l|c|c|c|c|}
\hline Time & $\begin{array}{c}\mathbf{5 , 2 5} \% \text { NaOCl } \\
\text { Mean Value } \\
\text { (Standard deviation) }\end{array}$ & $\begin{array}{c}\mathbf{0 , 1 \%} \text { OCT } \\
\text { Mean Value } \\
\text { (Standard deviation) }\end{array}$ & $\begin{array}{c}\mathbf{2 , 0 \%} \text { CHX } \\
\text { Mean Value } \\
\text { (Standard deviation) }\end{array}$ & $\begin{array}{c}\text { Saline } \\
\text { Mean Value } \\
\text { (Standard deviation) }\end{array}$ \\
\hline $\mathbf{3 0 ~ s e c}$ & $4,87(2,16)(\mathrm{a}, \mathrm{A})$ & $2,87(1,45)(\mathrm{a}, \mathrm{A})$ & $3,87(1,55)(\mathrm{a}, \mathrm{A})$ & \\
$\mathbf{1} \mathbf{~ m i n}$ & $1,87(2,85)(\mathrm{b}, \mathrm{A})$ & $1,75(2,18)(\mathrm{a}, \mathrm{b}, \mathrm{A})$ & $2,25(1,66)(\mathrm{a}, \mathrm{A})$ & \\
$\mathbf{5} \mathbf{~ m i n}$ & $0,37(0,74)(\mathrm{b}, \mathrm{A})$ & $0,62(1,06)(\mathrm{b}, \mathrm{A})$ & $0,62(0,91)(\mathrm{b}, \mathrm{A})$ & $31,00(7,57)(\mathrm{B})$ \\
\hline
\end{tabular}

*Different letters indicate significant difference (Kruskal-Wallis $\mathrm{P}<.05$ ). Capital letters indicate differences in horizontal direction. Lower-case letters indicate differences in vertical directions.

Table 5. Mean values of $\mathrm{CFU} \mathrm{mL} \mathrm{m}^{-1}$ of C.albicans after tested irrigation solutions application to the permanent teeth for different contact times.

\begin{tabular}{|l|c|c|c|c|}
\hline Time & $\begin{array}{c}\mathbf{5 , 2 5 \%} \text { NaOCI } \\
\text { Mean Value } \\
\text { (Standard deviation) }\end{array}$ & $\begin{array}{c}\mathbf{0 , 1 \%} \text { OCT } \\
\text { Mean Value } \\
\text { (Standard deviation) }\end{array}$ & $\begin{array}{c}\mathbf{2 , 0 \%} \text { CHX } \\
\text { Mean Value } \\
\text { (Standard deviation) }\end{array}$ & $\begin{array}{c}\text { Saline } \\
\text { Mean Value } \\
\text { (Standard deviation) }\end{array}$ \\
\hline $\mathbf{3 0}$ sec & $3,37(1,06)(\mathrm{a}, \mathrm{A})$ & $1,62(1,84)(\mathrm{a}, \mathrm{A})$ & $3,37(1,84)(\mathrm{a}, \mathrm{A})$ & \\
$\mathbf{1} \mathbf{~ m i n}$ & $1,33(1,30)(\mathrm{b}, \mathrm{A})$ & $1,12(1,35)(\mathrm{a}, \mathrm{A})$ & $1,00(1,60)(\mathrm{b}, \mathrm{A})$ & \\
$\mathbf{5} \mathbf{~ m i n}$ & $0,37(0,74)(\mathrm{b}, \mathrm{A})$ & $0,12(0,35)(\mathrm{a}, \mathrm{A})$ & $0,12(0,35)(\mathrm{b}, \mathrm{A})$ & $24,37(8,53)(\mathrm{B})$ \\
\hline
\end{tabular}

*Different letters indicate significant difference (Kruskal-Wallis $\mathrm{P}<.05$ ). Capital letters indicate differences in horizontal direction. Lower-case letters indicate differences in vertical directions.

\section{Discussion}

The bovine dentin model was modified as using human teeth in this study for testing the efficiency of medicaments (17). Recurring periapical inflammation of root-filled teeth may occur from viable bacteria residing within the root canal system and dentinal tubules (23). With the other test methods; for example collecting microbiological samples with absorbent paper cones; the samples may only be taken from the root canal micro- organisms, while it is not possible to take samples from the ones that are located inside the dentine tubules. The results of the saline treated negative control specimens found in the present study confirmed the predictability of the infection of the dentinal tubules with E.faecalis and C.albicans.

The effectiveness of irrigation solutions is directly related to the concentration as well as the volume (24). The choice of irrigant should be one that rapidly exerts 
its antimicrobial activity against resistant microorganisms found in the root canal and dentinal tubules. In the present study, all the tested solutions significantly reduced the microorganisms within dentinal tubules in a period of $5 \mathrm{~min}$.

Several researchers have pointed out the potential advantages of $\mathrm{CHX}$ as an antimicrobial medicament in endodontic therapy $(6,17,25-28)$. CHX is a broad-spectrum antimicrobial agent (29), that can be used effectively as an irrigant $(6,25-27)$, disinfect the dentinal tubules $(17,28)$, and be absorbed into the dentin (27).

As mentioned before; OCT, is a mouthrinse capable of exerting beneficial clinical effects upon plaque accumulation and gingivitis development (11). OCT has been demonstrated to be more effective than chlorhexidine as a means for prolonged bacterial antiadhesive activity (13).

Although quantitative bacterial reduction after chemomechanical preparation was significant, the samples treated with $\mathrm{NaOCl}$ were still positive regarding the presence of cultivable bacteria. If the antimicrobial activity was assumed as the only requirement of an endodontic irrigant, we could say according to the results of this study Octenidine can be preferred as an irrigantion solution. However, sodium hypochlorite possesses another very significant attributes that Octenidine is not known to posses. It has been reported that sodium hypochlorite has the ability to dissolve pulp tissues (6) and most clinicians consider the dissolution of pulp tissue by an irrigant to be of primary importance in the root canal instrumentation. Nevertheless, Octenidine may still be useful as an alternative endodontic irrigant. Its excellent antimicrobial properties support this inference.

Although preventive measures have reduced caries incidence, the premature loss of pulpally involved primary teeth remains to be a common problem. There are many morphologic changes that continually occur within primary teeth root canal anatomy. The root canal systems of primary molars frequently contain many ramifications and deltas between the canals rendering thorough debridement quite difficult (30). Therefore, the irrigation procedure for primary teeth is as important as permanent teeth.

It is worth emphasizing, however, that further clinical studies to assess the behavior of primary teeth submitted to endodontic therapy using the suggested auxiliary chemical solutions are of fundamental importance.

Additional studies will be needed to investigate Octenidine's relative safety and absence of unfavorable cosmetic and organoleptic properties. In addition, more information will be needed concerning probable dose-effectiveness, optimal regimens and modes of action like antibiofilm strategies. Thus results of this study may not express the actual efficacy of a medicament against microorganisms forming biofilm. These findings sug- gest that Octenidine may be useful as an endodontic irrigant. Its antimicrobial properties indicate it could be useful substitude in patients who are allergic to sodium hypochlorite.

\section{References}

1. Biffi JC, Rodrigues HH. Ultrasound in endodontics: a quantitative and histological assessment using human teeth. Endod Dent Traumatol. 1989;5:55-62.

2. Adriaens PA, Edwards CA, De Boever JA, Loesche WJ. Ultrastructural observations on bacterial invasion in cementum and radicular dentin of periodontally diseased human teeth. J Periodontol. 1988;59:493-503.

3. Cheung GS, Stock CJ. In vitro cleaning ability of root canal irrigants with and without endosonics. Int Endod J. 1993;26:334-43.

4. Fanning E. Effects of extraction of deciduous molars on the formation and eruption of their successors. The Angle Ortho. 1962:32: 44. 5. Ballesio I, Campanella V, Gallusi G, Marzo G. Chemical and pharmacological shaping of necrotic primary teeth. Eur J Paediatric Dent. 2002;3:133-40.

6. Jeansonne MJ, White RR. A comparison of $2.0 \%$ chlorhexidine gluconate and $5.25 \%$ sodium hypochlorite as antimicrobial endodontic irrigants. J Endod. 1994;20:276-8.

7. Spangberg L, Pascon EA. The importance of material preparation for the expression of cytotoxicity during in vitro evaluation of biomaterials. J Endod. 1988;14:247-50.

8. Busslinger A, Sener B, Barbakow F. Effects of sodium hypochlorite on nickel-titanium Lightspeed instruments. İnt Endod J. 1998;31:290-4.

9. Kaufman AY, Keila S. Hypersensitivity to sodium hypoclorite. J Endod. 1989;15:224-6.

10. Gomes BP, Ferraz CC, Vianna ME, Berber VB, Teixeira FB, Souza-Filho FJ. In vitro antimicrobial activity of several concentrations of sodium hypochlorite and chlorhexidine gluconate in the elimination of Enterococcus faecalis. İnt Endod J. 2001;34:424-8.

11. Patters MR, Anerud K, Trummel CL, Kornman KS, Nalbandian $\mathrm{J}$, Robertson PB. Inhibition of plaque formation in humans by octenidine mouthrinse. J Periodontal Res. 1983;18:212-9.

12. Shern RJ, Monell-Torrens E, Kingman A. Effect of two recently developed antiseptics on dental plaque and caries in rats. Caries Res. $1985 ; 19: 458-65$

13. Decker EM, Weiger R, Wiech I, Heide PE, Brecx M. Comparison of antiadhesive and antibacterial effects of antiseptics on Streptococcus sanguinis. Eur J Oral Sci. 2003;111:144-8.

14. Tandjung L, Waltimo T, Hauser I, Heide P, Decker EM, Weiger R. Octenidine in root canal and dentine disinfection ex vivo. Int Endod J. 2007;40:845-51

15. Ayhan H, Sultan N, Cirak M, Ruhi MZ, Bodur H. Antimicrobial effects of various endodontic irrigants on selected microorganisms. İnt Endod J. 1999;32:99-102.

16. Molander A, Reit C, Dahlén G, Kvist T. Microbiological status of root filled teeth with apical periodontitis. İnt Endod J. 1998;31:1-7.

17. Haapasalo M, Orstavik D. In vitro infection and disinfection of dentinal tubules. J Dent Res. 1987;66:1375-9.

18. Buck RA, Eleazer PD, Staat RH, Scheetz JP. Effectiveness of three endodontic irrigants at various tubular depths in human dentin. J Endod. 2001;27:206-8.

19. Waltimo TM, Sirén EK, Torkko HL, Olsen I, Haapasalo MP. Fungi in therapy-resistant apical periodontitis. İnt Endod J. 1997;30:96101.

20. Siqueira JF Jr, Sen BH. Fungi in endodontic infections. Oral Surg Oral Med Oral Pathol Oral Radiol Endod. 2004;97:632-41.

21. Delany GM, Patterson SS, Miller CH, Newton CW. The effect of chlorhexidine gluconate irrigation on the root canal flora of freshly extracted necrotic teeth. Oral Surg Oral Med Oral Pathol. $1982 ; 53: 518-23$ 
22. Goroncy-Bermes P. Investigation into the efficacy of disinfectants against MRSA and vancomycin-resistant enterococci. Zentralbl Hyg Umweltmed. 1998;201:297-309.

23. Vianna ME, Gomes BP, Berber VB, Zaia AA, Ferraz CC, de Souza-Filho FJ. In vitro evaluation of the antimicrobial activity of chlorhexidine and sodium hypochlorite. Oral Surg Oral Med Oral Pathol Oral Radiol Endod. 2004;97:79-84.

24. Baker NA, Eleazer PD, Averbach RE, Seltzer S. Scanning electron microscopic study of the efficacy of various irrigating solutions. J Endod. 1975;1:127-35.

25. Sjögren U, Figdor D, Persson S, Sundqvist G. Influence of infection at the time of root filling on the outcome of endodontic treatment of teeth with apical periodontitis. Int Endod J. 1997;30:297-306.

26. Kuruvilla JR, Kamath MP. Antimicrobial activity of $2.5 \%$ sodium hypochlorite and $0.2 \%$ chlorhexidine gluconate separately and combined, as endodontic irrigants. J Endod. 1998;24:472-6.

27. Parsons GJ, Patterson SS, Miller CH, Katz S, Kafrawy AH, New ton CW. Uptake and release of chlorhexidine by bovine pulp and dentin specimens and their subsequent acquisition of antibacterial properties. Oral Surg Oral Med Oral Pathol .1980;49:455-9.

28. Vahdaty A, Pitt Ford TR, Wilson RF. Efficacy of chlorhexidine in disinfecting dentinal tubules in vitro. Endod Dent Traumatol. 1993;9:243-8.

29. Emilson CG. Susceptibility of various microorganisms to chlorhexidine. Scand J Dent Res. 1977;85:255-65.

30. Baker BCW, Parsons KC, Mills PR, Williams GL. Anatomy of root canals. IV deciduous teeth. Aust Dent J. 1975;20:101-6.

The source of funding for the research was provided by Gazi University Scientific Resarch Projects Unit (No: 03/2006-02). 